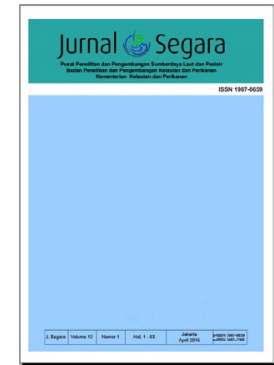

JURNAL SEGARA

http://ejournal-balitbang.kkp.go.id/index.php/segara

ISSN : 1907-0659

e-ISSN : 2461-1166

Nomor Akreditasi : 766/AU3/P2MI-LIPI/10/2016

\title{
FLUKTUASI NITRAT, FOSFAT DAN SILIKAT DI PERAIRAN PULAU BINTAN
}

\section{NITRATE, PHOSPHATE AND SILICATE SEASONAL DISTRIBUTION IN BINTAN WATER ISLAND}

\author{
Hanny Meirinawati \& Muswerry Muchtar \\ Pusat Penelitian Oseanografi, LIPI, Jakarta \\ Diterima: 24 Februari 2016 ; Diterima Setelah Perbaikan: 5 Mei 2017 ; Disetujui Terbit: 21 Juni 2017
}

\begin{abstract}
ABSTRAK
Pulau Bintan di Provinsi Kepulauan Riau memiliki wilayah pesisir dan sumber daya penghasil komoditas perikanan dan sebagai daerah wisata yang merupakan kontributor penting untuk pembangunan ekonomi dan kualitas hidup sehingga perlu dikelola dengan baik. Penelitian ini bertujuan untuk mengetahui kondisi perairan Bintan ditinjau dari variabilitas kandungan nitrat, fosfat, dan silikat secara spasial dan temporal sehingga dapat digunakan oleh pemerintahan setempat dan instansi terkait dalam mengembangkan dan mengelola perairan kawasan perairan Pulau Bintan. Pengambilan sampel untuk penelitian nutrien (nitrat, fosfat, dan silikat) di perairan timur Kepulauan Bintan telah dilakukan di 27 titik lokasi pada April dan Agustus 2014. Konsentrasi nutrien berfluktuasi pada April dan Agustus. Nilai rata-rata kosentrasi nitrat, fosfat, dan silikat pada April berturut-turut yaitu $0,0510 \pm 0,0014 \mathrm{mg} / \mathrm{L}, 0,0050 \pm 0,0026 \mathrm{mg} / \mathrm{L}$, dan 0,2660 $\pm 0,1655 \mathrm{mg} / \mathrm{L}$. Konsentrasi rata-rata nitrat, fosfat, dan silikat pada Agustus berturut-turut yaitu 0,0260 $\pm 0,0104 \mathrm{mg} / \mathrm{L}, 0,0160 \pm 0,0091 \mathrm{mg} / \mathrm{L}$ dan 0,057 $\pm 0,035 \mathrm{mg} / \mathrm{L}$. Konsentrasi nitrat, fosfat, dan silikat di perairan Bintan pada pengamatan April dan Agustus berfluktuasi.
\end{abstract}

Kata kunci: Nitrat, fosfat, silikat, perairan Bintan.

\section{ABSTRACT}

Bintan Island of Riau Islands province have coastal areas and resources fishery commodity producers and tourist areas are an important contributor to economic development and quality of life that needs to be done preservation. This study aims to determine the condition of the waters of Bintan in terms variability concentration of nitrate, phosphate, and silicate in spatial and temporal that can be used by local government in developing and managing the waters of Bintan island waters. Samplings for the study of nutrients (nitrate, phosphate, and silicate) in the eastern waters of Bintan Island were carried out in 27 point location in April and August 2014. Nutrient concentrations are fluctuated in April and August average concentrations of nitrate, phosphate, and silicate in April respectively, are $0.0510 \pm 0.0014 \mathrm{mg} / \mathrm{L}, 0.0050 \pm 0.0026 \mathrm{mg} / \mathrm{L}$, and $0.2660 \pm 0.1655 \mathrm{mg} / \mathrm{L}$. Average concentrations ofnitrate, phosphate, and silicate in August respectively, are $0.0260 \pm 0.0104 \mathrm{mg} / \mathrm{L}, 0.0160 \pm 0.0091 \mathrm{mg} / \mathrm{Land} 0.0570$ $\pm 0.0350 \mathrm{mg} / \mathrm{L}$. The concentrations of nitrate, phosphate, and silicate in the waters of Bintan in April and August are fluctuated.

Keywords: Nitrate, phosphate, silicate, Bintan waters.

\section{PENDAHULUAN}

Daerah pesisir merupakan daerah yang aktif dari interaksi global antara tanah dan laut yang sangat sensitif terhadap gangguan manusia, disamping itu juga merupakan daerah yang penting dalam pengelolaan lingkungan. Material dari daratan dimodifikasi dan ditransfer ke pesisir melalui berbagai proses yang mengatur fluks dari sumber alami maupun antropogenik ke laut terbuka (Zhang et al., 2004). Wilayah pesisir dan sumber daya yang dimilikinya merupakan kontributor penting untuk pembangunan ekonomi dan kualitas hidup. Pemanfatan sumber daya tersebut dapat meningkatkan pendapatan masyarakat setempat baik melalui perikanan, pertanian, dan pariwisata. Oleh karena itu, pelestarian wilayah pesisir merupakan hal yang perlu dijadikan prioritas utama untuk pembangunan ekonomi (Ounissi et al., 2014).

Pulau Bintan merupakan salah satu bagian dari gugusan pulau yang berada di wilayah Provinsi Kepulauan Riau. Perairan Bintan termasuk wilayah

Corresponding author:

Jl. Pasir Putih II Ancol Timur, Jakarta Utara 14430. Email: hanny.meirinawati@gmail.com 
perairan yang diandalkan sebagai penghasil bahan tambang bauksit, penghasil komoditas perikanan, dan sebagai daerah wisata yang banyak dikunjungi oleh wisata baik lokal ataupun mancanegara (DKPPKE Kota Tanjung pinang, 2012).

Kondisi perairan pulau Bintan sangat penting untuk diketahui karena berkaitan dengan kehidupan biota laut. Salah satunya dengan mengetahui kandungan parameter kimia nutrien yaitu nitrat, fosfat dan silikat. Nutrien tersebut berperan dalam produktivitas primer laut, siklus nutrien, dan jaring makanan (Mohamed \& Amil, 2015). Selain itu, nitrogen $(\mathrm{N})$, fosfor $(\mathrm{P})$ dan silikon (Si) merupakan elemen biogenik yang menentukan geokimia karakteristik laut dan khususnya derajat eutrofikasi (Li et al., 2015).

Nutrien dimanfaatkan oleh organisme laut yang terdapat di permukaan maupun di kedalaman yang dapat dicapai oleh sinar matahari (zona eufotik) di mana proses fotosintesis berlangsung (Zehr \& Ward, 2002).

Nitrogen merupakan nutrien penting untuk fitoplankton dan merupakan elemen pembatas pertumbuhan fitoplankton di laut (Collos \& Berges, 2003) sedangkan Fosfor (P) adalah nutrien utama pada produksi primer laut (Ruttenberg, 2003). Masing-masing fosfat dan nitrat mengandung unsur nitrogen dan fosfor yang berasal dari alam, buangan antropogenik, dekomposisi material organik, limbah pertanian, sisa pakan peternakan, dan dari buangan domestik dan industri yang masuk ke laut (Lu et al., 2011).

Pertumbuhan populasi manusia telah menyebabkan perubahan ekosistem seperti pembukaan lahan pertanian dan aktivitas domestik pemukiman sehingga akan berdampak pada sikus biogeokimia karbon, nitrogen dan fosfor. Kelebihan $\mathrm{N}$ yang dibutuhkan untuk pertumbuhan tanaman di daerah pertanian dapat mengakibatkan beberapa kemungkinan yaitu $\mathrm{N}$ tersebut terakumulasi dalam tanah, bergerak dari daratan ke permukaan perairan, bermigrasi ke air tanah atau memasuki atmosfer melalui penguapan amonia dan produksi nitro oksida. Kegiatan manusia juga berdampak pada penambahan fosfor. Sejumlah besar $P$ ditambang dan dibuat untuk bahan pupuk. Kelebihan $P$ yang tidak diserap oleh tumbuhan ini akhirnya terakumulasi di dalam tanah selama bertahun-tahun (Smith et al., 1999). Pada 2011 telah dilakukan pengukuran kandungan nitrat dan fosfat oleh Dinas Kelautan dan Perikanan Bintan. Kandungan nitrat yang diperoleh berkisar antara 0,145 $\mathrm{mg} / \mathrm{L}$ - 0,687 $\mathrm{mg} / \mathrm{L}$, sedangkan kandungan fosfat berkisar antara 0,005 mg/L - 0,028 mg/L (DKP Bintan, 2011). Jumlah penduduk yang terus meningkat setiap tahunnya mengakibatkan semakin banyaknya limbah domestik. Data BPS tahun 2016 menyebutkan bahwa pada tahun 2013 jumlah penduduk di pulau Bintan sebanyak 346.100 jiiwa dan meningkat pada tahun 2014 menjadi 350.846 jiwa (BPS Kepri, 2016).

Selain dari limbah domestik, limbah dari industri dan limbah dari pertanian turut menyumbangkan masukan nitrogen dan fosfat. Tercatat pada tahun 2013 terjadi peningkatan sebanyak 8 industri besar dan 28 industri kecil dan menengah. Selain itu, Bintan memiliki lahan seluas 1.247,9 Ha yang digunakan untuk pertanian (BPS Bintan, 2014). Limbah zat organik perkotaan, industri dan pupuk yang mengandung unsur nitrogen dan fosfat yang tinggi yang masuk ke suatu

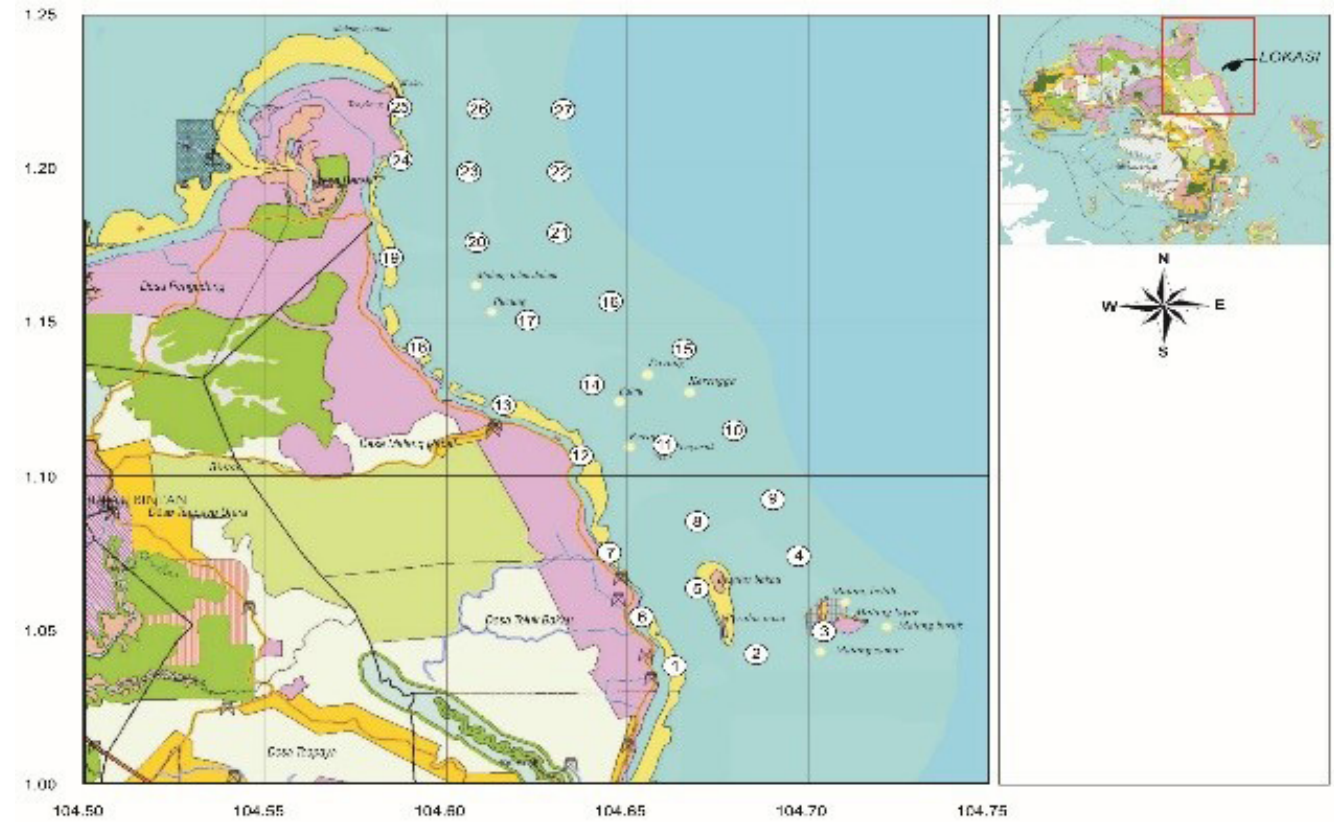

Gambar 1. Stasiun pengambilan sampel di perairan Bintan, April dan Agustus 2014. 
perairan melalui sungai akan merangsang pertumbuhan fitoplankton dan fitobentik yang akan menyebabkan efek beragam kepada perairan tersebut dan ekosistem laut sekitarnya (Karydis \& Dimitra, 2012). Tercatat limbah total nitrogen dari daratan sebesar 243,52 ton/tahun dengan sumbangan terbesar berasal dari aktivitas hotel dan restoran yaitu $50,38 \%$ sedangkan dari sumber yang lain masing-masing sebesar $41,87 \%$ (aktivitas penduduk), 7,44\% (peternakan) dan 0,31\% oleh aktivitas pertanian (Lestari, 2014).

Peristiwa eutrofikasi di wilayah laut pesisir dan muara, merupakan permasalahan yang terus meningkat di dunia terutama disebabkan pengayaan nutrien nitrogen dan fosfor (Ahtiainen et al., 2014). Unsur $\mathrm{N}$ anorganik mempengaruhi struktur fitoplankton suatu lingkungan perairan, contohnya kelimpahan konsentrasi nitrat menyebabkan peledakan diatom disuatu perairan (Lomas \& Glibert, 1999).

Tulisan ini bertujuan untuk mengetahui kondisi perairan Bintan ditinjau dari variabilitas kandungan nitrat, fosfat, dan silikat secara spasial dan temporal yang nantinya dapat digunakan oleh pemerintahan setempat dan instansi terkait dalam mengembangkan dan mengelola perairan kawasan perairan Pulau Bintan.

\section{METODE PENELITIAN}

Pengambilan sampel dilakukan pada kedalaman $5 \mathrm{~m}$ dari lapisan permukaan laut di 27 stasiun pada April dan Agustus 2014 di perairan timur Kepulauan Bintan (Gambar 1). Sampel air laut untuk nitrat, fosfat dan silikat diambil dengan menggunakan Botol Nansen kemudian dimasukkan ke dalam botol poli etilen volume $500 \mathrm{ml}$. Sebelum dianalisis, sampel terlebih dahulu disaring dengan menggunakan kertas saring berbahan nitrosellulosa dengan ukuran pori 0,45 $\mu \mathrm{m}$. Analisis dilakukan kurang dari 12 jam setelah sampel dikoleksi dari lapangan.

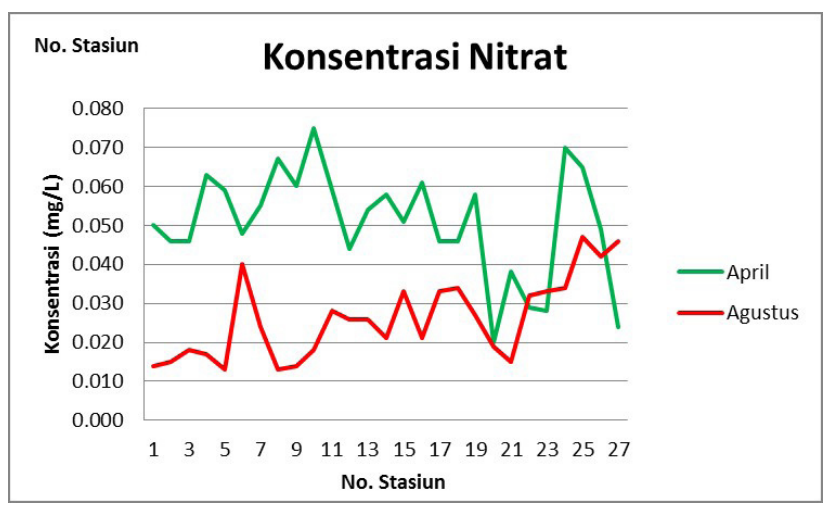

Gambar 2. Konsentrasi Nitrat pada April dan Agustus 2014.

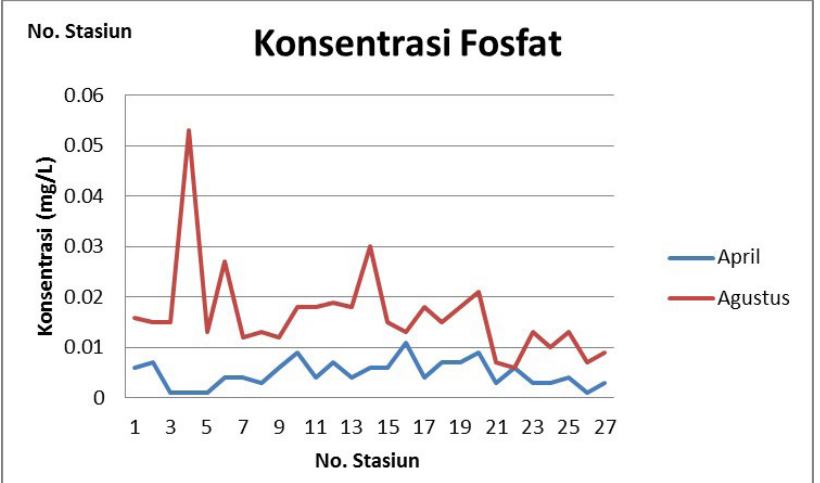

Gambar 3. Konsentrasi Fosfat pada April dan Agustus 2014.

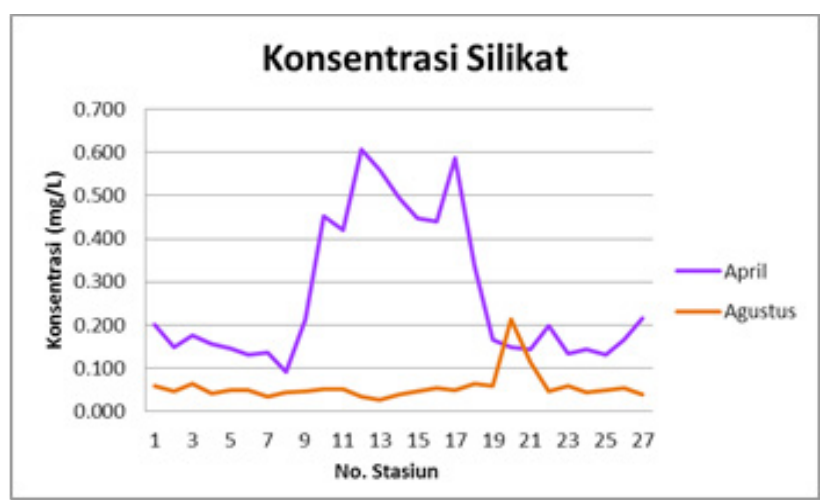

Gambar 4. Konsentrasi Silikat pada April dan Agustus 2014.

Nutrien dianalisis secara spektrofotometri menggunakan alat spektrofotometer Shimadzu UV1201V. Panjang gelombang yang digunakan yaitu 885 $\mathrm{nm}$ (fosfat) (Murphy \& Riley, 1962), 543 nm (nitrat), dan $810 \mathrm{~nm}$ (silikat) (Strickland \& Parsons, 1972). Selanjutnya, untuk mengetahui perbedaan antara kondisi perairan secara spasial dan temporal dianalisis statistik dengan menggunakan ANOVA 2 jalur tanpa interaksi.

\section{HASIL DAN PEMBAHASAN}

Konsentrasi rata-rata nitrat, fosfat, dan silikat pada April berturut-turut yaitu 0,051 $\pm 0,0014 \mathrm{mg} / \mathrm{L}$, $0,005 \pm 0,0026 \mathrm{mg} / \mathrm{L}$ dan 0,266 $\pm 0,1655 \mathrm{mg} / \mathrm{L}$. Konsentrasi rata-rata nitrat, fosfat, dan silikat pada Agustus berturut-turut yaitu 0,026 $\pm 0,0104 \mathrm{mg} / \mathrm{L}$, $0,016 \pm 0,0091 \mathrm{mg} / \mathrm{L}$ dan 0,057 $\pm 0,0350 \mathrm{mg} / \mathrm{L}$.

Jika dibandingkan dengan April 2014, konsentrasi nitrat dan silikat pada Agustus 2014 mengalami penurunan sedangkan konsentrasi fosfat mengalami kenaikan. Data hasil penelitian dapat dilihat pada Gambar 2, 3, dan 4. 


\section{Nitrat}

Konsentrasi nitrat pada April 2014 adalah 0,020 - 0,075 mg/L dengan rata-rata 0,051 $\pm 0,0014 \mathrm{mg} / \mathrm{L}$. Pada Agustus 2014 konsentrasi nitrat adalah 0,013 $0,047 \mathrm{mg} / \mathrm{L}$ dengan rata-rata $0,026 \pm 0,0104 \mathrm{mg} / \mathrm{L}$. Secara umum lebih kecil jika dibandingkan dengan perairan Gresik yang konsentrasi nitratnya 0,008 - 0,257 $\mathrm{mg} / \mathrm{L}$ (Simanjuntak, 2013). Jika dibandingkan dengan lokasi di Teluk Jakarta yang memiliki konsentrasi nitrat 0,0458 - 0,1857 mg/L, konsentrasi nitrat di Bintan juga jauh lebih kecil (Riksawati, 2008). Ini disebabkan karena perairan Bintan, pengaruh daratannya jauh lebih kecil bila dibandingkan dengan perairan Gresik dan Teluk Jakarta yang pengaruh daratannya lebih besar seperti buangan pertanian, pertambakan dan kawasan industri. Konsentrasi nitrat di Bintan tidak jauh berbeda dengan penelitian kandungan nutrien di Estuari Cisadane, konsentrasi nitrat yang diamati pada Juli 2005 berkisar antara 0,002 - 0,021 mg/L dan pada November 2005 berkisar antara 0,003-0,047 mg/L (Muchtar \& Simanjuntak, 2008). Selain itu, diketahui konsentrasi nitrat di Kepulauan Tambelan berkisar antara $0,005-0,013 \mathrm{mg} / \mathrm{L}$ (Suherman \& Prayitno, 2012).

Periode April termasuk ke dalam Musim Peralihan I sedangkan periode Agustus termasuk ke dalam Musim Timur. Musim Peralihan I terjadi pada saat pergantian Musim Barat ke Musim Timur. Pada

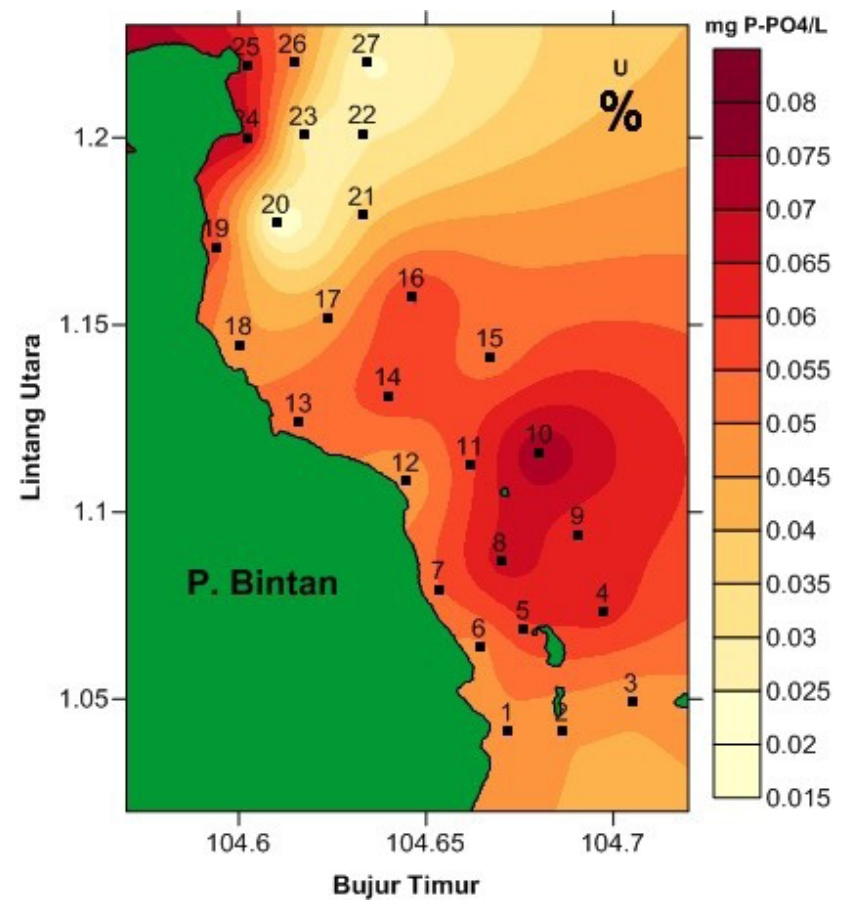

(A) musim Timur, matahari berada di belahan bumi utara sehingga Benua Asia memiliki suhu yang lebih tinggi dari Benua Australia menyebabkan tekanan udara di Benua Asia lebih rendah dari Benua Australia. Oleh karena itu angin bertiup dari Benua Australia menuju Benua Asia (Wyrtki, 1961). Limpasan dari daratan merupakan faktor penyumbang terbesar konsentrasi nutrien dan dipengaruhi oleh faktor iklim yaitu angin dan curah hujan. Konsentrasi nitrat menurun dari April (Musim Peralihan I) ke Agustus (Musim Timur) mungkin disebabkan pada musim timur telah memasuki musim kemarau. Dengan tidak terjadinya hujan maka berkurang pula limpasan dari daratan.

Distribusi nutrien di perairan dipengaruhi oleh faktor musim (faktor biotik, suhu dan deposisi basah), faktor fisis (upwelling dan pencampuran air), biologis (konsumsi oleh produsen primer dan regenerasi oleh bakteri), dan muatan antropogenik (Bianchi et al., 1994; Wang et al., 2012).

Pola sebaran konsentrasi nitrat yang tinggi pada April berada pada lokasi tengah di Desa Malang Rapat, stasiun 8, 9, 10, 11 (Gambar 5A). Selain itu konsentrasi nitrat yang tinggi terdapat di stasiun 24 dan stasiun 25 di Desa Tanjung Berakit. Hal ini karena stasiun tersebut dekat dengan daratan yang merupakan sumber masukan nutrien ke laut. Pada Agustus 2014 rata-rata konsentrasi nitrat yang teramati di lokasi lebih kecil jika dibandingkan dengan April

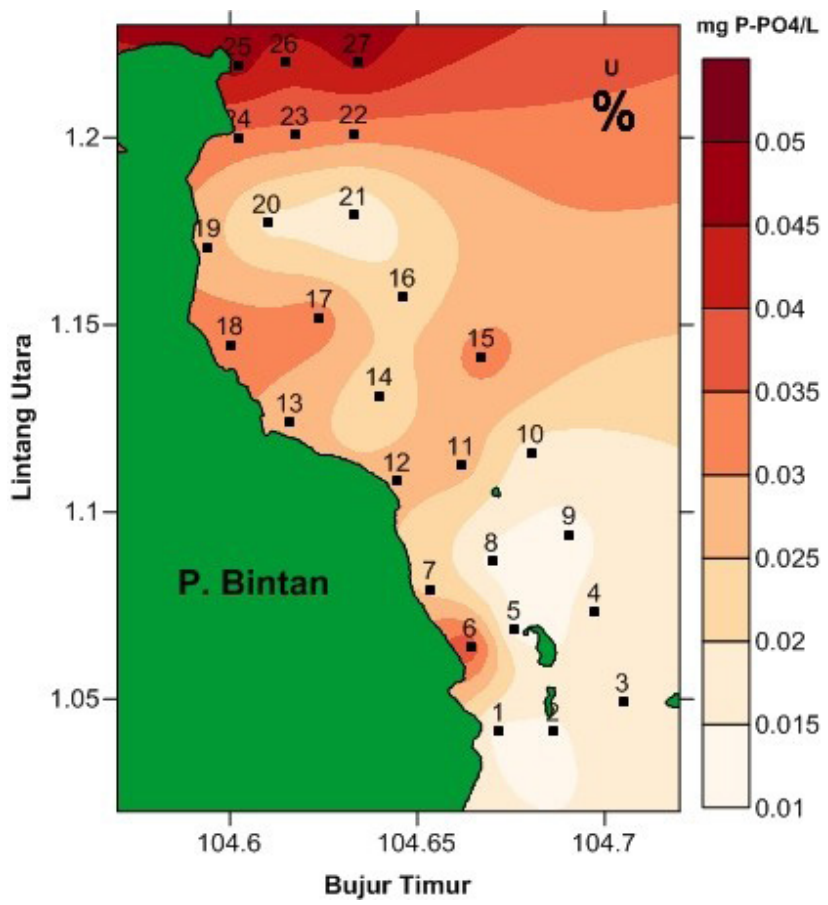

(B)

Gambar 5. Pola sebaran nitrat di perairan timur Kepulauan Bintan April (A) Agustus (B) 2014. 
2014. Pola sebaran konsentrasi nitrat yang tinggi pada Agustus 2014 (Gambar 5B) berada di lokasi Desa Tanjung Berakit, stasiun 22, 23, 24, 25, 26 dan 27. Hal ini mungkin disebabkan karena pengaruh daratan yang dekat dengan stasiun pengamatan juga masukan nutrien yang dibawa dari perairan Laut China Selatan. Konsentrasi nitrat yang tinggi menunjukkan ketersediaan sumber nitrogen yang cukup melimpah bagi pertumbuhan fitoplankton.

Hasil analisis statistik dengan menggunakan ANOVA 2 jalur tanpa interaksi menunjukkan bahwa tidak terdapat perbedaan nyata antar stasiun ( $F$ hitung $<\mathrm{F}$ tabel). Sebaliknya, secara temporal menunjukkan bahwa terdapat perbedaan nyata antar musim ( $F$ hitung > F tabel).

Peningkatan pasokan nitrogen $(\mathrm{N})$ dan fosfat $(P)$ ke perairan pesisir diakibatkan oleh meningkatnya populasi manusia di wilayah pesisir, industrialisasi, dan intensifikasi pertanian (Ferreira et al., 2011) Pupuk, limbah, limbah hewan, masukan atmosfer, dan budi daya pesisir berkontribusi untuk peningkatan konsentrasi nutrien di perairan pesisir, dengan bukti kuat bahwa peningkatan nutrien telah menyebabkan meningkatnya biomassa fitoplankton dan produksi primer di beberapa lokasi (Gowen et al., 2012).

Tinggi rendahnya nitrat juga sangat tergantung pada kandungan oksigen terlarut. Pada saat kadar oksigen rendah, keseimbangan bergerak menuju ammonia, sedangkan pada saat kadar oksigen tinggi keseimbangan bergerak menuju nitrat (Hamzah \& Saputro, 2013). Wilayah pesisir lebih dekat dengan daratan sehingga limpasan dari daratan akan masuk terlebih dahulu ke wilayah pesisir kemudian akan bergerak menuju laut.

Menurut Lalli \& Parsons (1997), fitoplankton dapat tumbuh dengan baik pada rentang konsentrasi nitrat $0,028-0,140 \mathrm{mg} / \mathrm{L}$ dan konsentrasi nitrat di perairan Bintan masih berada pada rentang tersebut sehingga dapat dikatakan bahwa di perairan Bintan cukup subur untuk pertumbuhan dan perkembangan fitoplankton.

\section{Fosfat}

Fosfor dalam bentuk ortofosfat, memainkan peran kunci dalam fotosintesis (produktivitas primer) (Paytan \& McLaughin, 2007). Fosfat ini digunakan oleh fitoplankton untuk metabolisme (Cotner \& Biddanda, 2002). Konsentrasi fosfat di perairan Bintan pada April 2014 sebesar $0,001-0,011 \mathrm{mg} / \mathrm{L}$ dengan ratarata $0,005 \pm 0,0026 \mathrm{mg} / \mathrm{L}$. Pola sebaran konsentrasi fosfat yang tinggi berada di lokasi Desa Malang Rapat stasiun 10, 12, 15, 16 (Gambar 6A). Pola sebaran fosfat ini mirip dengan pola sebaran nitrat yang memiliki konsentrasi tinggi pada lokasi Desa Malang Rapat. Pada Agustus 2014, konsentrasi fosfat yang dihasilkan 0,006 - 0,053 mg/L dengan rata-rata 0,016 $\pm 0,0091 \mathrm{mg} / \mathrm{L}$. Secara keseluruhan konsentrasi fosfat pada Agustus lebih tinggi bila dibandingkan dengan pengamatan April 2014. Pola sebaran konsentrasi fosfat yang tinggi pada Agustus terdapat di lokasi Desa Teluk Bakau stasiun 4 (Gambar 6B). Konsentrasi fosfat di perairan Bintan sama halnya dengan nitrat lebih rendah bila dibandingkan dengan perairan Gresik yang mempunyai konsentrasi fosfatnya 0,031 - 0,255 $\mathrm{mg} / \mathrm{L}$ dan Teluk Jakarta yang konsentrasi fosfatnya berkisar antara 0,0087 - 0,1583 mg/L (Simanjuntak, 2013, Riksawati, 2008).

Jika dibandingkan dengan penelitian di lokasi yang berbeda seperti di Estuari Cisadane pada Juli 2005, konsentrasi fosfat yang diamati berkisar antara $0,003-0,084 \mathrm{mg} / \mathrm{L}$ dan pada November 2005 berkisar antara 0,003 - 0,233 mg/L (Muchtar \& Simanjuntak, 2008). Tingginya konsentrasi fosfat di perairan Estuari Cisadane ini karena banyaknya sungai-sungai yang mengalir ke estuari yang membawa limbah dari daratan. Rendahnya konsentrasi fosfat teramati di Kepulauan Tambelan yang berkisar antara 0,001 - 0,004 mg/L (Suherman \& Prayitno, 2012). Bila dibandingkan dengan di Kepulauan Tambelan maka konsentrasi fosfat di perairan Bintan lebih tinggi akan tetapi konsentrasi fosfat di perairan Bintan ini masih masuk sama dengan baku mutu air laut untuk 870 biota laut yang ditetapkan KLH tahun 2004 sebesar $0,015 \mathrm{mg} / \mathrm{L}$.

Sepertinya perbedaan musim saat pengambilan sampel merupakan faktor yang paling dominan mempengaruhi perbedaan data yang didapat. Pada Agustus 2014, konsentrasi rata-rata fosfat yang dihasilkan lebih besar jika dibandingkan dengan April 2014. Pola temporal fosfat ini berbeda dengan nitrat. Mungkin ini disebabkan karena sedikit fosfat yang dimanfaatkan oleh fitoplankton. Hasil analisis statistik dengan menggunakan ANOVA 2 jalur tanpa interaksi menunjukkan bahwa tidak terdapat perbedaan nyata antar stasiun ( $F$ hitung $<F$ tabel). Sebaliknya, secara temporal menunjukkan bahwa terdapat perbedaan nyata antar musim ( $F$ hitung $>F$ tabel).

Rentang konsentrasi fosfat supaya fitoplankton dapat tumbuh dengan baik yaitu 0,00062 - 0,0155 mg/L (Lalli \& Parsons, 1997). Konsentrasi rata-rata perairan Pulau Bintan masih berada pada rentang tersebut, sehingga dapat dikatakan perairan Bintan masih subur dan tidak mengalami pengayaan fosfat.

\section{Silikat}

Silikat merupakan senyawa yang diperlukan untuk pertumbuhan diatom dan beberapa spons. 
Selain itu silikat juga dimanfaatkan oleh radiolaria, silicoflagelata, beberapa spesies choanoflagelata, dan beberapa picocyanobacteria. Silikat berasal dari pelapukan batuan benua dan sedimen yang terlarut. Silikat tersebut kemudian dialirkan ke daerah pesisir oleh sungai dan air tanah. Diatom merupakan penyumbang utama fitoplankton di wilayah pesisir dan mendukung perikanan (Treguer \& De La Rocha, 2013).

Konsentrasi silikat pada April 2014 berkisar antara 0,091 - 0,607 $\mathrm{mg} / \mathrm{L}$ dengan nilai rata-rata $0,2660 \pm 0,1655 \mathrm{mg} / \mathrm{L}$. Konsentrasi silikat pada Agustus 2014 sebesar 0,027 - 0,214 mg/L dengan rata-rata $0,0570 \pm 0,0350 \mathrm{mg} / \mathrm{L}$. Secara keseluruhan terlihat bahwa konsentrasi perairan Bintan lebih rendah bila dibandingkan dengan perairan Gresik sebesar 1,938 -15,118 mg/L. Tingginya konsentrasi silikat pada perairan Gresik disebabkan lokasi yang dekat dengan muara sungai yang merupakan tempat akumulasi buangan limbah daratan (Simanjuntak, 2013). Konsentrasi silikat di Bintan juga lebih rendah jika dibandingkan dengan lokasi di Teluk Jakarta yang konsentasi silikatnya berkisar antara 0,2094 - 0,9828 $\mathrm{mg} / \mathrm{L}$ (Riksawati, 2008). Penelitian lain di Estuari Cisadane didapatkan konsentrasi silikat pada Juli 2005 berkisar antara 0,118 - 10,74 mg/L dan pada November 2005 berkisar antara 0,456 - 7,88 mg/L (Muchtar \& Simanjuntak, 2008). Namun konsentrasi perairan Bintan ini tidak jauh berbeda bila dibandingkan dengan penelitian kandungan nutrien yang telah dilakukan di Kepulauan Tambelan dengan konsentrasi silikat berkisar antara 0,078 - 0,126 mg/L (Suherman \& Prayitno, 2012).

Pola sebaran silikat yang tinggi pada April 2014 terdapat di Lokasi desa Malang Rapat stasiun 12, 13, 14, 17 (Gambar 7A). Pola sebaran yang ditunjukkan sama dengan pola sebaran nitrat dan fosfat pada April 2014, hal ini mungkin disebabkan karena lokasi yang dekat dengan daratan. Pelapukan batuan yang dekat dengan daratan membuat konsentrasi silikat lebih tinggi.

Bila dibandingkan dengan April 2014, ratarata konsentrasi silikat pada Agustus 2014 lebih kecil. Pola sebaran silikat tertinggi terjadi pada Agustus 2014 tercatat di lokasi Desa Tanjung Berakit stasiun 20 (Gambar 7 B). Pola distribusi silikat yang berbeda diduga disebabkan oleh pola sirkulasi air dan proses absorbsi organisme. Hasil analisis statistik dengan menggunakan ANOVA 2 jalur tanpa interaksi menunjukkan bahwa tidak terdapat perbedaan nyata antar stasiun ( $\mathrm{F}$ hitung $<\mathrm{F}$ tabel). Sebaliknya, secara temporal menunjukkan bahwa terdapat perbedaan nyata antar musim ( $F$ hitung $>F$ tabel).

Menurut Lalli \& Parsons (1997), fitoplankton dapat tumbuh dengan baik pada rentang konsentrasi silikat 0,014 - 0,140 mg/L. Konsentrasi silikat di perairan Bintan pada April lebih tinggi dari batas atas rentang tersebut, ini mengindikasikan pada April terdapat diatom dalam jumlah sedikit yang memanfaatkan silika tersebut.

Suatu perairan dikatakan eutrofik jika kandungan fosfatnya > dari 0,011 $\mathrm{mg} / \mathrm{L}$ dan kandungan nitratnya $>0,005 \mathrm{mg} / \mathrm{L}$ (Ignitiades et al., 1992). Secara umum, gambaran di atas memperlihatkan bahwa kualitas air laut perairan timur Kepulauan Bintan pada April 2014 dan Agustus 2014 tergolong dalam perairan eutrofik. Pengaruh musim terhadap beban masukkan nutrien telah dilakukan Pello et al. (2014) di TelukAmbon Dalam. Penelitiannya menunjukkan bahwa konsentrasi nutrien berbeda untuk setiap musim. Fluktuasi nutrien yang terjadi bisa disebabkan oleh beberapa faktor adanya masukan dari darat, pemanfaatan nutrien melalui proses fotosintesis, proses adsorpsi dan sedimentasi oleh padatan tersuspensi (Sanusi, 2004).

Ketersediaan nutrien di perairan pesisir dipengaruhi oleh adanya interaksi proses-proses biokimiawi, aktivitas manusia di darat yang masuk ke perairan dan faktor fisika kimiawi daerah neritik dan oseanik (Sanusi, 2004).

\section{KESIMPULAN}

Dari hasil pengamatan konsentrasi nitrat, fosfat, dan silikat di perairan Bintan dapat disimpulkan bahwa konsentrasi nitrat, fosfat, dan nitrat di perairan Bintan pada pengamatan April dan Agustus berfluktuasi. Tinggi tendahnya konsentrasi nitrat, fosfat, dan silikat di perairan ini selain tergantung pada lokasi stasiun penelitian juga dipengaruhi keadaan sekelilingnya, sepertiadanya pengaruhdaratanyangmenyumbangkan buangan-buangan organik yang berasal dari limbah pertanian, industri, dan rumah tangga melalui sungaisungai yang mengalir ke perairan tersebut.

\section{PERSANTUNAN}

Ucapan terimakasih penulis sampaikan kepada Pusat Penelitian Oseanografi LIPI yang telah memberikan dana bagi kegiatan penelitian ini dan kepada Bapak Afdal, M.Si. selaku koordinator kegiatan penelitian ini.

\section{DAFTAR PUSTAKA}

Ahtiainen, H., Artell, J., Elmgren, R., Hasselstrom, L. \& Håkansson, C. (2014). Baltic Sea nutrient reductions - What should we aim for? Journal of Environmental Management, 145, 9-23.

Bianchi, M., Morin, P. \& Le Corre, P. (1994). Nitritication rates and nitrate distribution in the Almeria-Oran 
frontal system (eastern Alboran Sea). J. Marine Syst., 5, 327-342.

Badan Pusat Statistik Provinsi Kepulauan Riau. (2016). http://kepri.bps.go.id/linkTableDinamis/view/id/7.

Badan Pusat Statistik Kabupaten Bintan. (2014). Statistik Daerah Kabupaten Bintan 2014. BPS Kabupaten Bintan. 34 hal.

Collos,Y. \& Berges, J.A. (2003). Nitrogen Metabolism In Phytoplankton. In C. M. Duarte [ed.], Encyclopedia of Life Support Systems. EOLSS Publishers (UNESCO).

Cotner, J.B. \& Biddanda, B.A. (2002). Small Players, Large Role: Microbial Influence on Biogeochemical Processes in Pelagic Aquatic Ecosystems. Ecosystems, 5, 105-121.

DKPPKE Kota Tanjungpinang. (2012). Laporan Akhir Penyususnan Rencana Zonasi dan rencana Pengelolaan Kawasan Habitat Gonggong (Strombus sp.) Kota Tanjungpinang. Tanjung Pinang: Dinas Kelautan Perikanan Pertanian Kehutanan dan Energi.

Ferreira, J.G., Andersen, J.H., Borja, A., Bricker, S.B., Camp, J., Cardoso da Silva, M., Garces, E., Heiskanen, A.-S., Humborg, C., Ignatiades, L., Lancelot, C., Menesguen, A., Tett, P., Hoepffner, N. \& Claussen, U. (2011). Overview of eutrophication indicators to assess environmental status within the European Marine Strategy Framework Directive. Estuar. Coast. Shelf Sci, 93, 117-131.

Gowen, R.J., Mckinney, A., Tett, P., Bresnan, E., Davidson, K., Harrison, P.J., Milligan, S., Mills, D.K., Silke, J. \& Crooks, A.M. (2012). Anthropogenic nutrient enrichment and blooms of harmful phytoplankton. Oceanogr. Mar. Biol., 50, 65-126.

Hamzah, F. \& Saputro, P.D. (2013). Pola Sebaran Logam Berat dan Nutrien pada Musim Kemarau di Estuari Perancak, Bali. J.Segara, 9(2), 117127.

Ignatiades, L., Karydis, M. \& Vounatsou, P. (1992). A possible method for evaluating oligotrophy and eutrophication based on nutrient concentrations. Marine Pollution Bulletin, 24(5), 238-243.

Karydis, M. \& Dimitra, K. (2012). Eutrophication and environmental policy in the Mediterranean Sea: a review. Environ Monit Assess., 184, 4931-4984.
(2004). Baku Mutu Air Laut untuk biota laut. Dalam: Keputusan Menteri Negara Lingkungan Hidup No.51 Tahun 2004 Tentang Baku Mutu Air Laut. KLH. Jakarta: 32 hal.

Lalli, C.M. \& Parsons, T.M. (1997). Biological Oceanography, An Introduction. Second Edition. Elsevier Butterworth-Heinemann.

Lestari, F., Damar, A., Soewardi, K. \& Adrianto, K. (2014). Fluks Nitrogen Anorganik Terlarut di Perairan Pesisir Kota Tanjung Pinang, Propinsi Kepulauan Riau. J. Segara, 10 (1), 51-59.

Li, H.M., Zhang, C.S., Han, X.R. \& X.Y. Shi. 2015. Changes in concentrations of oxygen, dissolved nitrogen, phosphate, and silicate in the southern Yellow Sea, 1980-2012: Sources and seaward gradients. Estuarine, Coastal and Shelf Science 163: 44-55.

Lomas, M.W., \& Glibert, P.M. (1999). Interactions between $\mathrm{NH} 4+$ and NO3- uptake and assimilation: comparison of diatoms and dinoflagellates at several growth temperatures. Mar. Biol., 133, 541-551.

Lu, X.X., Li, S., He, M., Zhou,Y., Bei, R., Li, L. \& Ziegler, A.D. (2011). Seasonal changes of nutrient fluxes in the Upper Changjiang basin: An example of the Longchuanjiang River, China. Journal of Hydrology, 405, 344-351.

Mohamed, K.N. \& R. Amil. 2015. Nutrients enrichment experiment on seawater samples at Pulau Perhentian, Terengganu. Procedia Environmental Sciences 30: 262-267.

Muchtar, M. \& Simanjuntak, M. (2008). Karakteristik dan Fluktuasi Zat Hara Fosfat, Nitrat, dan Derajat Keasaman $(\mathrm{pH})$ di Estuari Cisadane pada Musim yang Berbeda dalam Ekosistem Estuari Cisadane. Jakarta: LIPI Press.

Murphy, J. \& Riley, J.P. (1962). Modified single solution method for the determination of phosphate in natural waters. Analyt. Chem. Acta, 27,31-36.

Ounissi, M., Ziouch, O.R. \& Aounallah, O. (2014). Variability of the dissolved nutrient $(\mathrm{N}, \mathrm{P}, \mathrm{Si})$ concentrations in the Bay of Annaba in relation to the inputs of the Seybouse and Mafragh estuaries. Marine Pollution Bulletin, 80, 234-244.

Paytan, A. \& McLaughlin, K. (2007). The Oceanic Phosphorus Cycle. Chem. Rev., 107 (2), 563-576.

Kementerian Lingkungan Hidup Republik Indonesia. 
Pello, F.S., Adiwilaga, E.M., Huliselan, N.V. \& Damar, A. (2014). Pengaruh Musim Terhadap Beban Masukkan Nutrien di Teluk Ambon Dalam. Jurnal Bumi Lestari, 14(1), 63 - 73.

Realino, B., Teja, A., Wibawa., Dedy, A., Zahrudin. \& Asmi, M.N. (2007). Pola Spasial dan Temporal Kesuburan Permukaan Laut di Indonesia. Balai Riset dan Observasi Kelautan, Badan Riset Kelautan dan Perikanan, Departemen Kelautan dan Perikanan, Negara, Jembrana, Bali, Indonesia.

Riksawati, A. (2008). Kandungan Nutrien dan Produktivitas Primer Perairan Muara Angke, Teluk Jakarta. Skripsi. Institut Pertanian Bogor.

Ruttenberg, K.C. (2003). The global phosphorus cycle, in: Schlesinger, W.H. (ed), Treatise on geochemistry, Vol 8. Elsevier, pp. 585-643.

Sanusi, H.S. (2004). Karakteristik Kimiawi dan Kesuburan perairan Teluk Pelabuhan Ratu Pada Musim Barat Dan Timur. Jurnal IImu-ilmu Perairan dan Perikanan Indonesia,11(2), 93-100.

Simanjuntak, M. (2013). Kualitas perairan Gresik, Jawa Timur: kandungan Nutrien, Oksigen Terlarut dan Derajat Keasaman. Jurnal Oseanologi dan Limnologi, 39(2), 125-262.

Smith, V.H., Tilman, G.D. \& Nekola, J.C. (1999). Eutrophication: impacts of excess nutrient inputs on freshwater, marine, and terrestrial ecosystems. Environmental Pollution,100, 179-196.

Strickland, J.D.H. \& Parsons, T.R. (1972). A Practical Handbook of Seawater Analysis, Bulletin 167 (Second edition). Fisheries Research Board of Canada. Ottawa. 310 pp.

Suherman \& Prayitno, H.B. (2012). Examination of The Chemical Properties of Seawater of The Tambelan Islands. Indo.J.Chem., 12 (3), 235-241.

Treguer, P.J. \& De La Rocha, C.L. (2013). The World Ocean Silica Cycle. Annu. Rev. Mar. Sci.,5, 5.15.25 .

United States Environmental Protection Agency. (2014). http://water.epa.gov/type/rsl/monitoring/ vms57.cfm

Wang, Y., Liu, D., Dong, Z., Di, B. \& Shen, X. (2012). Temporal and spatial distributions of nutrients under the influence of human activities in Sishili Bay, northern Yellow Sea of China. Marine Pollution Bulletin, 64, 2708-2719.
Wyrtki, K. (1961). Physical Oceanography of The Southeast Asian Water. NAGA Report Vol 2. Scripps Inst. Oceanography. The University of California. La Jolla, California.

Zehr, J.P. \& Ward, B.B. (2002). Nitrogen cycling in the ocean: New perspectives on processes and paradigms. Appl. Environ. Microbiol., 68 (3),10151024.

Zhang, J., Yu, Z.G., Raabe, T., Liu, S.M., Starke, A., Zou, L., Gao, H.W. \& Brockmann, U. (2004). Dynamics of inorganic nutrient species in the Bohai seawaters. Journal of Marine Systems, 44, 189-212. 